\title{
LABORATORIO
}

\section{Evaluación del líquido hidatídico como sustrato de sensibilización en la obtención de anticuerpos policlonales de uso en ELISA coproantigénica}

\author{
DANILO VARGAS*, RAFAEL BONET*, CLAUDIA JOFRÉ* y SERGIO CAMPANO**
}

\section{ANTIGENIC EXTRACT OF BOVINE HYDATIDID CYST LIQUID IN THE POLICLONAL ANTIBODIES PRODUCTION TO USE IN COPROANTIGENIC ELISA}

There was evaluated rabbit's policlonal antibodies production against an antigenic extract arising from bovine hydatid cyst liquid, with E.I.T. assay (Western Blot). SPC ${ }_{L H}$ recognized the same antigenic epitopes identify by $S P C_{T A}$. Also was estudied the potential application of $S P C_{L H}$ in Coproantigenic ELISA as a sensibilization substratum. With this purpose 50 fecal samples of dogs with or without infection were carried out by the implemented ELISA. It was determinated a technical sensibility of $64 \%$, a specificity of 100\%, PPV and NPV of $100 \%$ and $97,6 \%$, respectively.

Key words: Policlonal serum, Hidatidic liquid, ELISA, Coproantigenic.

\section{INTRODUCCIÓN}

El complejo Equinococosis/Equinococosis quística representado cuatro especies del género Echinococcus, cuya reproducción y ciclos vitales transcurren en diversos mamíferos como hospederos intermediarios y en carnívoros domésticos y salvajes como hospederos definitivos ${ }^{1}$.

El agente etiológico en Chile, es el Echinococcus granulosus, cuyo hábitat principal es el intestino delgado del perro doméstico (Canis familiaris). Los huevos son eliminados a través de las heces, que al ser consumidos por ungulados domésticos $y$ accidentalmente por el hombre, producen la enfermedad denominada equinococosis quística (Hidatidosis), desarrollándose el estado larval o hidátide.

Es una patología con notificación obligatoria desde 1951 por su impacto social, económico y en salud animal. Siendo clasificada en la lista B de enfermedades de la Oficina Internacional de Epizootias².

El diagnóstico de la equinococosis canina se efectúa principalmente, mediante la purga con bromhidrato de arecolina y la visualización macroscópica del parásito en las heces. Una alternativa en el diagnóstico es una modalidad de ELISA, que permite la identificación de coproantígenos propios de vermes en el intestino del perro. Esta técnica inmunodiagnóstica presenta sensibilidades sobre el $80 \%$ mientras que la especificidad del género alcanza al $98 \%{ }^{3}$.

\footnotetext{
* Laboratorio de Diagnóstico Molecular DIAMOLABÒ, Universidad Mayor. Casilla 234, Correo 35. Las Condes, Santiago, Chile.Email: dvargas@umayor.cldiamolab@umayor.cl

** Servicio Agrícola y Ganadero, Ministerio de Agricultura, Lo Aguirre, Chile.
} 
El presente estudio contempló la evaluación de anticuerpos policlonales dirigidos contra extractos de proteínas del líquido de quistes hidatídicos y su potencial aplicación en ELISA Coproantigénica.

\section{MATERIAL Y MÉTODOS}

I.- Material Biológico: El líquido hidatídico se obtuvo de quístes hidatídicos de bovinos (localización hepática y/o pulmonar), beneficiados en planta faenadora La Pintana, Región Metropolitana (RM). La fertilidad se determinó por tinción con Rojo Neutro 4 .

El material fecal para la estandarización de ELISA Coproantigénica se obtuvo de dos perros, donde uno fue infectado experimentalmente con protoescólices fértiles y el otro fue dosificado con praziquantel $(5 \mathrm{mg} / \mathrm{Kg})$.

La aplicabilidad de los anticuerpos de conejo en ELISA Coproantigénica se efectuó en 50 muestras fecales de perros con o sin infección a E. granulosus determinado por inmunoensayo con Kit comercial.

II.- Preparación Antígenos: Los extractos antigénicos de quistes hidatídicos bovinos, se efectuó según técnica descrita previamente ${ }^{5}$. La concentración de proteína en $\mathrm{mg} / \mathrm{ml}$, se midió por el Método de Bradford ${ }^{6}$.

El atígeno de E. granulosus se obtuvo de perros infectados experimentalmente ${ }^{7}$.

III.- Obtención anticuerpos Policlonales: La obtención de los anticuerpos policlonales de conejos (SPF) dirigidos contra antígenos de líquido de quiste hidatídico $\left(\mathrm{SPC}_{\mathrm{LH}}\right)$, se efectuó por inoculación, según procedimiento descrito establecidos previamente ${ }^{7}$, con algunas modificaciones. Brevemente, la primera inoculación (día 1) se realizó vía intramuscular con una solución compuesta por 1,5 mg de antígeno diluido en suero fisiológico; emulsificada 1:1 con Coadyuvante Freund Completo (v/v). Al día 12 se procedió a una reinoculación, pero con Coadyuvante Incompleto. Un refuerzo (día 26) se realizó vía subcutánea con el Coadyuvante Incompleto. Al día 42 se les extrajo sangre a los conejos, la cual fue centrifugada e inactivada $\left(56^{\circ} \mathrm{C}\right.$ por 30 minutos). El suero obtenido se almacenó a $-20^{\circ} \mathrm{C}$, hasta su uso.

IV.-Evaluación de anticuerpos policlonales: Los anticuerpos policlonales ( $\mathrm{SPC}_{\mathrm{LH}}$ ) fueron evaluados por Electroinmuno Transferencia
(E.I.T. $^{8}$, con algunas modificaciones ${ }^{5}$. Brevemente, la identificación de los epítopes antigénicos se efectuó por comparación de $\mathrm{SPC}_{\mathrm{LH}}$ con anticuerpos policlonales dirigidos contra antígenos somáticos de E. granulosus $\left(\mathrm{SPC}_{\mathrm{TA}}\right)$, obtenidos del perro control infectado experimentalmente.

V.- Ensayo ELISA coproantigénica: La técnica se efectuó, según el procedimiento descrito por Craig et al (1994) $)^{7}$, con algunas modificaciones. El ensayo estandarizado, utilizó microplacas de poliestireno (Sarstedt ${ }^{\circledR}$ ), sensibilizadas con suero hiperinmune de conejo $\left(\mathrm{SPC}_{\mathrm{LH}}\right)$ diluidos $1 / 200$ en solución tampón carbonato/bicarbonato (CBC) $\mathrm{pH}$ 9,6. Los extractos antigénicos fecales controles se incubaron a $37^{\circ} \mathrm{C}$ en cámara húmeda por 30 minutos. Posterior a los lavados, la placa se incubó con $\mathrm{SPC}_{\mathrm{LH}}$. El conjugado utilizado correspondió a una anti IgG de conejo marcada con peroxidasa $\left(\operatorname{Sigma}{ }^{\circledR}\right)$, a una dilución de $1 /$ 1.000 que se incubó a $37^{\circ} \mathrm{C}$ por 30 minutos. El revelado se efectuó con ortofenildiamina (OPD). Las lecturas se realizaron a una $\lambda$ de $490 \mathrm{~nm}$.

El estudio se llevó a cabo con 25 muestras de material antigénico, provenientes de fecas de perros confirmados por Kit comercial y 25 fecas de perros sin la parasitosis. El nivel de corte se obtuvo con el promedio de la absorbancia (DO) de los controles negativos, más una vez la desviación estándar. La determinación de los parámetros técnicos de sensibilidad, especificidad, valores predictivos de los positivos y de los negativos (VPP, VPN) se efectuó por procedimientos estandares9. Además se evaluó la concordancia, según el Índice Kappa, entre nuestros resultados para ELISA Coproantigénica y un Kit comercial.

\section{RESULTADOS Y DISCUSIÓN}

Sin duda, las técnicas de tamizaje inmunoenzimáticas como ELISA proporcionan información vital en los programas de control de las enfermedades parasitarias, ya que permiten estudiar un gran número de muestras, presentando sensibilidades elevadas. Dado lo anterior, el propósito de éste estudio fue evaluar la producción de anticuerpos policlonales de conejos dirigidos a proteínas de líquido de quistes hidatídicos fértiles de origen bovino, a fin de ser utilizados como anticuerpos de captura en ELISA 
Tabla 1. Resultados ELISA coproantigénica

\begin{tabular}{lccr}
\hline $\begin{array}{l}\text { Individuos } \\
\text { Prueba }\end{array}$ & Infectados & Normales & Totales \\
\hline Positiva & $16 \mathrm{a}$ & $0 \mathrm{~b}$ & $16 \mathrm{a}+\mathrm{b}$ \\
Negativa & $9 \mathrm{c}$ & $25 \mathrm{~d}$ & $34 \mathrm{c}+\mathrm{d}$ \\
Total & $25 \mathrm{a}+\mathrm{c}$ & $25 \mathrm{~b}+\mathrm{d}$ & $50 \mathrm{n}$ \\
\hline
\end{tabular}

coproantigénica aplicada a la identificación de $E$. granulosus en muestras fecales de perros con infección.

I.- Producción anticuerpos policlonale: $\mathrm{La}$ Figura 1 resume los resultados de la evaluación de los $\mathrm{SPC}_{\mathrm{LH}}$ por E.I.T., utilizando como control de referencia anticuerpos policlonales dirigidos a antígenos somáticos de E. granulosus $\left(\mathrm{SPC}_{\mathrm{TA}}\right)$. Se puede determinar que el patrón de hibridación antigénico de ambos sueros policlonales, con antígeno de Líquido Hidatídico Bovino es muy similar, lo cual se evidencia por la identificación de epítopes del complejo antigénico B, caracterizado por su elevada especificidad, tal como se ha descrito por otros investigadores ${ }^{10}$.

II.- Aplicación ELISA coproantigénica con SPC $_{\text {LH }}$ : La Tabla 1 muestra los resultados de los ensayos por ELISA coproantigénica a 50 muestras fecales provenientes de perros controles. Se determinó una Sensibilidad de 64\% y una Especificidad de 100\%. Los Valores Predictivos para los Positivos (VPP) y para los Negativos (VPN) fueron de $100 \%$ y $73,5 \%$, respectivamente. La concordancia de los resultados, comparando un kit comercial y la ELISA Coproantigénica implementada mostró una correlación clasificada como Buena, reflejada en un índice Kappa de 0,64. Lo anterior implica que los índices de concordancia esperados (pe) se asemejan bastante a los índices de concordancia observados (po $)^{9}$.

$\mathrm{Si}$ consideramos como referencia los parámetros de sensibilidad (76\%) y Especificidad (95\%) de un kits, estos han mostrado resultados confiables según estudios realizados en Punta $\operatorname{Arenas}^{11}$ (7\% de positivos) y en la localidad de Putre $^{12}$ (34,5\% de fecas positivas). Sin embargo, presentan como desventajas comparativas su costo, hasta el riesgo biológico por manipulación de material altamente contaminante.

$\mathrm{Si}$ los valores predictivos técnicos son aplicados a la prevalencia de equinococcosis presente en la XI Región, con un $6,5 \%{ }^{13}$, se

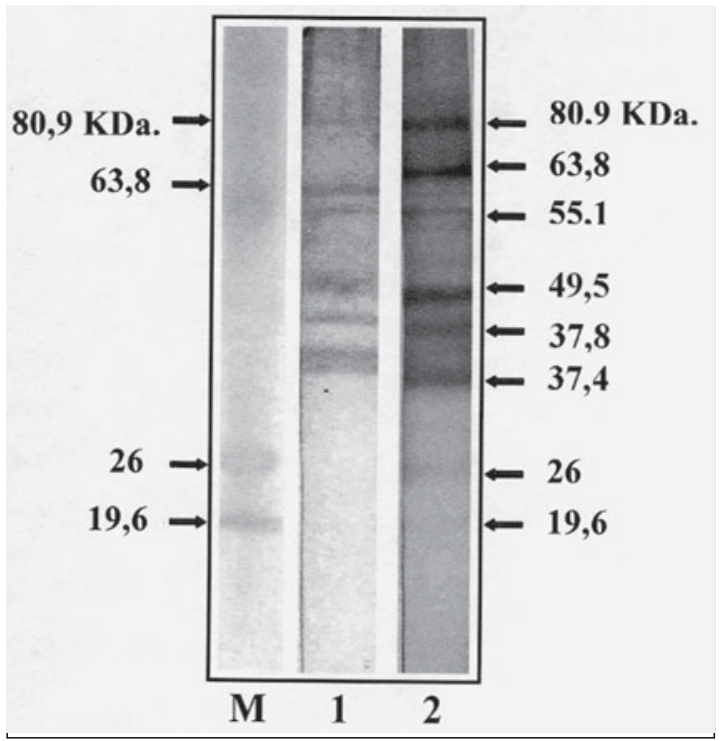

Figura 1. Evaluación de anticuerpos policlonales de conejo dirigidos contra estados adulto y larval de Echinococcus granulosus, por EIT.

obtuvo valores para VPP y VPN de un $100 \%$ y $97,6 \%$, respectivamente. Lo anterior se traduce en que existe un $100 \%$ de probabilidad de estar infectado cuando el resultado de la ELISA implementada muestre positividad. A su vez la probabilidad de que un individuo con resultado negativo sea correctamente diagnosticado es de un $97,6 \%$.

Finalmente, el $\mathrm{SPC}_{\mathrm{LH}}$ se sugiere como una valiosa alternativa metodológica aplicada a ELISA coproantigénica como prueba tamiz. De esta forma evitar la infección experimental de perros, previo tratamiento con Bromhidrato de Arecolina, técnica caracterizada por presentar un alto grado de bioseguridad y un bajo costo, factor importante al elegir una prueba diagnóstica.

\section{RESUMEN}

Se evaluó la producción de anticuerpos policlonales de conejos, dirigido a un extracto antigénico procedente de líquido de quistes hidatídicos, por aplicación de la E.I.T. Los epítopes antigénicos reconocidos por $\mathrm{SPC}_{\mathrm{LH}}$ fueron similares a los identificados por $\mathrm{SPC}_{\mathrm{TA}}$. También se estudió su potencial aplicación como sustrato de sensibilización en ELISA Coproantigénica, con tal propósito se ensayaron 50 
muestras fecales de perros con y sin infección, mostrando una Sensibilidad de 64\%, Especificidad $100 \%$. Además VPP y VPN mostraron resultados de $100 \%$ y $97,6 \%$, respectivamente.

\section{REFERENCIAS}

1.- ECKERT J, SCHANTZ P M, GASSER R B, et al. Geographic distribution and prevalence. In: Eckert J, Gemmell MA, Meslin FX, Pawlowski ZS, editors. WHO/ OIE manual on echinococcosis in humans and animals: a public health problem of global concern. Paris: The World Health Organization; 2001; p.100-42.

2.- OFICINA INTERNACIONAL DE EPIZOOTIAS (OIE). Organización Mundial de Sanidad Animal. 2001. [en línea], [http:/www. oie. int/hs2/report.asp], [consulta: 13 de marzo, 2002].

3.- CAMPANO S. Estado actual del control de la Equinococosis/Hidatidosis en la X, XI y XII Regiones de Chile. Futuro y perspectivas. EN: Jornadas Internacionales de Infectología Pediátrica, $\left(2^{a}\right.$, Julio, Temuco, Chile). 2000.

4.- HIMONAS C, ANTONIADOU K, PAPADOPOULOS E. Hydatidosis of food animals in greece: prevalence of cysts containing viable protoscoleces. J Helminthol 1994; 68: 311-3.

5.- VARGAS D, BONET R, CAMPANO S, et al. Evaluación epidemiológica de las técnicas de ELISA y electroinmuno transferencia en el diagnóstico de la hidatidosis ovina en la XI Región de Chile. Parasitología al Día 2001; 25: 85-92.

6.- BRADFORD M. A rapid and sensitive method for microgram quantities of protein utilizing the principle of protein-dye bindin. Annal Biochemestry 1976; 72: 248-54.

7.- CRAIG P S, ALLAN J C. Cproantigen test for Echinococcus granulosus. Protocol guide. Dept. of Biological Sciences, University of Salford. 1994.

8.- TOWBIN H, STAEHELIN T, GORDON J. Electrophoretic transfer of proteins from polyacriylamide gels to nitrocellulose sheets: procedure and some applications. Proc Natl Acad Sci USA 1979; 76: 4350.

9.- CURA E, WENDEL S. Manual de procedimientos de control de calidad para los laboratorios de serología de los bancos de sangre. PAHO/HCT/94.21. 1994; 2: 13-20.

10.- LIGHTOWLERS M, LIU DY, HARALAMBOUS A, RICKARD MD. Subunit composition and specificity of the major cyst fluid antigens of Echinococcus granulosus. Mol Biochem Parasitol 1989; 37: 17182.

11.- ALVARADO V. Detección de Coproantígenos de Echinococcus granulosus en fecas caninas Mediante ELISA Modalidad Sandwich en Áreas Públicas de la Ciudad de Punta Arenas. (Tesis Med. Vet.) Santiago, Chile, Universidad Mayor. Facultad de Ciencias Silvoagropecuarias. 2002. 83 págs.

12.- MAUREIRA F. Estudio de la Presencia de Antígenos Fecales de Echinococcus granulosus en perros del Altiplano Chileno (Putre, $1^{a}$ Región) Mediante el Ensayo Inmunoenzimático (Sandwich ELISA)". (Tesis Med. Vet.) Santiago, Chile, Universidad Mayor. Facultad de Ciencias Silvoagropecuarias. 1999. 68 págs.

13.- CHILE. Ministerio de Agricultura. S.A.G. En: Informe Anual 1998 del Programa Control de la Hidatidosis Ovina. S.A.G.-F.N.D.R. Región de Aysén, Chile, Ministerio de Salud. Código B.I.P.: 1100004-0. Marzo 1999. págs. 1-7.

\section{CONSTRUYE Y VENDE Av. Lib. B. O'Higgins 969, Piso $12^{\circ}$ F: 6712267, Fax: 6962129 e-mail: nahmias@netline.cl SANTIAGO}

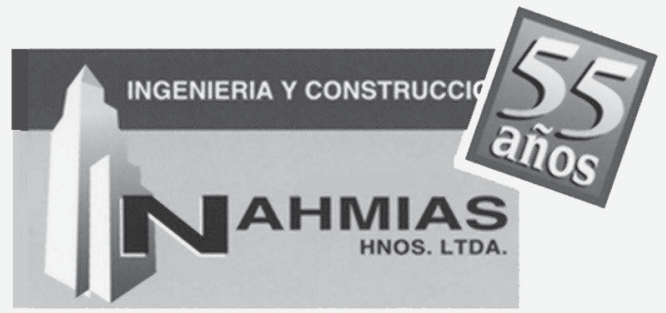

